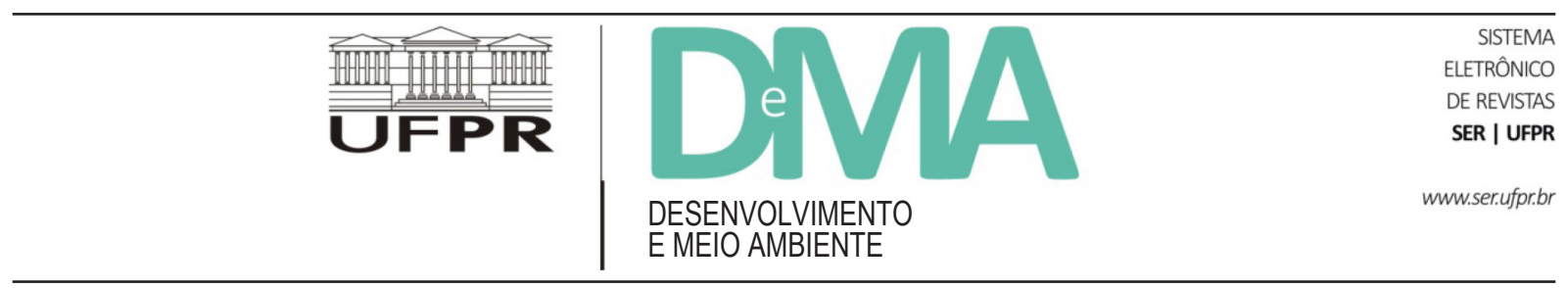

\title{
A comunicação ambiental e suas potencialidades no enfrentamento dos dilemas socioambientais ${ }^{1}$
}

\section{Environmental Communication and its Potentialities in the Social Problems Confrontation}

\author{
Myrian DEL VECCHIO DE LIMA ${ }^{1,2^{*}}$, Pedro da Silva JÚNIOR ${ }^{1}$, Eloísa Belling LOOSE ${ }^{1}$, Danielle Scheffelmeier \\ MEI $^{2}$, Thaís Cristina SCHNEIDER ${ }^{1}$, Valéria Sousa DUARTE ${ }^{1}$ \\ ${ }^{1}$ Programa de Pós-Graduação em Meio Ambiente e Desenvolvimento (PPGMade), Universidade Federal do Paraná (UFPR), Curitiba, PR, Brasil. \\ ${ }^{2}$ Programa de Pós-Graduação em Comunicação (PPGCom), Universidade Federal do Paraná (UFPR), Curitiba, PR, Brasil. \\ *E-mail de contato: myriandel@gmail.com
}

Artigo recebido em 22 de fevereiro de 2015, versão final aceita em 10 de junho de 2015.

RESUMO O artigo apresenta reflexões sobre a noção de comunicação ambiental, a fim de contribuir na construção do conceito que define esta área considerada especializada e de interface. Defende-se que tal área, situada no imbricamento entre os campos da comunicação e do meio ambiente, caracteriza-se por englobar fundamentos e perspectivas de ambos, ressaltando seu caráter interdisciplinar. Inicialmente são apresentadas as bases epistemológicas dos dois campos, com o objetivo de enfatizar as articulações práticas e teóricas que ocorrem entre eles. Faz-se, então, uma revisão de literatura acerca do termo "comunicação ambiental", considerando autores nacionais e internacionais, e argumenta-se que esta não se resume a tratar de temáticas características da área ambiental. Por fim, busca-se refletir sobre as possibilidades da comunicação ambiental para auxiliar nas ações de enfrentamento dos problemas socioambientais contemporâneos.

Palavras-chave: comunicação; meio ambiente; comunicação ambiental; interfaces; epistemologia.

ABSTRACT This paper provides reflections over the notion of environmental communication, seeking to contribute on the construction of the concept that defines this kind of communication, considered specialized and of interface. The argument stated is that environmental communication is characterized by embracing perspectives and fundamentals of both the communication and the environmental fields, since it is situated in their interweave, emphasizing its interdisciplinary character. Initially, the epistemological bases of both fields are presented, in order to highlight the practical and theoretical articulations that occur between them. A literature review about the term is then provided, considering national and international authors, followed by the argumentation that environmental communication is not simply about dealing with thematic features of the environmental field. Finally, some reflections on its possibilities to assist in coping actions of contemporary social and environmental problems are offered.

Keywords: communication; environment; environmental communication; interfaces; epistemology.

${ }^{1}$ Este artigo foi apresentado como trabalho no $2^{\circ}$ Encontro Interdisciplinar de Comunicação Ambiental (Eica), realizado na Universidade Federal de Sergipe (UFS), em maio de 2013. 


\section{Introdução}

Muito se fala hoje a respeito de problemas relacionados ao meio ambiente, como a poluição, o desmatamento, a perda da biodiversidade e as mudanças climáticas de origem antropogênica, para citar apenas alguns exemplos. De fato, essas são questões que se intensificaram nas últimas décadas, com o avanço da modernidade, marcado, entre inúmeros fenômenos, pela chamada separação sociedade-natureza. Nesse aspecto, configura-se um cenário de conflitos e crises, que são fundamentalmente associados à maneira como a humanidade se relaciona com as demais espécies e seu meio, e cujos sintomas se fazem presentes no cotidiano, de forma visível ou não, afetando a qualidade de vida e a concepção do que é e como as pessoas se envolvem com o meio ambiente.

Em tal contexto, marcado por rápidas transformações, é preciso refletir sobre as possibilidades que cada área do conhecimento apresenta para contribuir no enfrentamento de tais crises. O presente trabalho traz algumas ponderações acerca da noção de comunicação ambiental ${ }^{2}$, desenvolvidas no âmbito do grupo de pesquisa que reúne esses autores, que a entendem como sendo a comunicação especializada na divulgação de informações e conhecimentos socioambientais aos mais diferentes públicos e âmbitos institucionais, a partir da compreensão dos fundamentos do campo ambiental. Trata-se, portanto, de uma construção situada nas interfaces entre os campos da comunicação e do meio ambiente, abarcando saberes, princípios epistemológicos e questionamentos sobre as práticas ambientais de ambos.

O texto se organiza a partir do entendimento de que as interfaces disciplinares têm constituído um instigante e rico campo de estudos, que permitem a convivência produtiva, e sempre desafiadora, de pesquisadores e profissionais de diferentes áreas do conhecimento. Inicialmente, expõem-se os campos da comunicação e do meio ambiente - que, epistemologicamente, con- formaram-se a partir do início e meados do século XX, respectivamente, e que vêm alterando e evoluindo seu conjunto de teorias e metodologias em anos recentes.

Essa evolução ocorre pela emergência de novos paradigmas de conhecimento e de novas questões, crises e conflitos em áreas teóricas e empíricas limítrofes, em um contexto de acelerados processos de mundialização e mudanças globais. Destacam-se, nesse âmbito, as transformações no próprio modo de pensar e fazer a ciência que vêm se dando a partir da segunda metade do século XX, como analisa Felinto (2014, p. 24), ao falar de uma crise da ciência "que vai do otimismo mais ingênuo quanto aos poderes da ciência ao questionamento radical de todo fundamento sólido para o saber".

A comunicação, um campo em mutação e questionamentos, também altera vários de seus aspectos teóricos e passa a debater/analisar outros, ao final do século XX, quando cientistas sociais se vêm instados a deslocar seu olhar dos estudos e conceitos majoritariamente centrados nos meios de comunicação de massa (MCM) e na sociedade e cultura de massa - com seus fenômenos de produção e consumo de mensagens e produtos homogêneos e hegemônicos condicionados pelas novas mídias digitais on-line. Ganha atenção, portanto, a emergente "sociedade em rede", metáfora de Castells (1999) para representar uma sociedade global que se conecta por meio de fluxos permanentes e interativos de redes de comunicação físicas e virtuais, que levanta, segundo Rüdiger (2014, p. 157), dois novos princípios com relação às alterações recentes do campo:

\footnotetext{
O primeiro é o da indústria cultural, o do processo de transformação da cultura em mercadoria, que hoje, a passos rápidos, se vai reduzindo ao negócio com a notícia e o entretenimento. O segundo, ainda mais radical, é o da cibernetização, o do processo de redução da resistência à informação eletrônica, que, vivenciado através das manifestações da chamada cibercultura, etapa superior da indústria cultural, nos empurra para os limites da utopia da comunicação.”.
}

\footnotetext{
${ }^{2}$ Cabe explicitar que, no entendimento dos autores, o adjetivo “ambiental” engloba aspectos sociais e humanos, extrapolando, portanto, a noção de meio ambiente dada apenas em referência aos aspectos ecológicos. Tal concepção deriva dos próprios fundamentos do campo ambiental, que vem justamente discutir e tratar das relações entre sociedade e natureza.
} 
Cabe notar também que, no bojo das perspectivas científicas mais recentes, reforça-se o caráter interdisciplinar do campo da comunicação, marcado pela possibilidade de tomar como objeto os mais variados fenômenos sociais.

O meio ambiente, por sua vez, como campo de estudos que se volta para o entendimento da crise ambiental que emerge nos anos 1950-1960, passa a inserir, ao lado da ecologia e do estudo dos ecossistemas e sua degradação, as visões das ciências sociais e econômicas, para dar conta de uma questão que se torna cada vez mais onipresente no planeta: o conflito natureza-sociedade. Essa problemática se estende às questões da preservação e conservação do meio ambiente natural, apropriado pelo ser humano como espaço para extração e produção de matérias-primas, produtos agrícolas, consumismo e descarte de resíduos, passando por seu atrelamento às questões de justiça ambiental, pobreza e desigualdade social até a produção de cenários futuristas quanto à sobrevivência do ser humano, agente principal da crise ambiental e de modelos de desenvolvimento em curso.

Tais questões têm levado ao entendimento da necessidade de se consolidar uma "racionalidade ambiental" que, segundo Leff (2006, p. 21), "vai se constituindo ao contrastar-se com as teorias, o pensamento e a racionalidade da modernidade" com um conceito que emergiu "da matriz discursiva do ambientalismo nascente" (Ibidem) e, aos poucos, foi criando um universo de sentido próprio.

Uma vez situados os dois campos, o artigo traz uma revisão de literatura sobre o conceito de comunicação ambiental, considerando autores internacionais e nacionais. Desenvolve-se, então, a noção de comunicação ambiental ora proposta, levando em conta as diversas aproximações que vêm ocorrendo entre meio ambiente e comunicação em variados âmbitos.

Os estudos teóricos e as práticas no campo ambiental têm se confrontado com novas problemáticas decorrentes das recentes mudanças globais em seus diversos aspectos, e veem crescer a necessidade de lançar mão dos recursos comunicacionais que garantam sua visibilidade na agenda pública, como também das melhores formas de gestão de informação e comunicação, e de estratégias de promoção de participação e mobilização social para avançar democraticamente. Por sua centralidade no panorama das configurações socioeconômicas, políticas e culturais do segundo milênio, as duas áreas de conhecimento apresentam imbricações no campo das teorias, práticas e processos técnicos, revelando um conjunto de interesses e perspectivas comuns que resulta no conceito de comunicação ambiental. Ressalta-se, portanto, a proposição de que essa interface não se resume apenas a tratar de temas relacionados ao meio ambiente, o que não definiria nosso entendimento de comunicação ambiental, mas se dá na abordagem da temática e dos objetos evidenciados, seja em uma pesquisa científica, seja em uma prática socioambiental em comunicação, de forma a agregar a epistemologia e os saberes dos dois campos ${ }^{3}$.

Por fim, o texto revela um esforço analítico-reflexivo dos autores sobre como a comunicação ambiental pode e deve colaborar para o enfrentamento de problemas socioambientais, ao explicitar aspectos atrelados ao exercício da cidadania e participação da sociedade, que dependem da disponibilização/sistematização de informações, construção e divulgação de conhecimentos, e preparação do público para o entendimento das questões envolvidas. Parte-se do pressuposto de que a comunicação ambiental aqui referida é a base para que processos de mobilização e de articulação cidadã sejam desencadeados e fortalecidos.

\section{Dois campos em diálogo}

\subsection{O campo ambiental}

Ainda em fase de construção, o campo centrado nas relações entre sociedade e natureza traz intrinsecamente em sua constituição a interdisciplinaridade, já

\footnotetext{
${ }^{3}$ Michel Foucault (1972 apud Rüdiger, 2014, p. 58) propõe uma distinção entre ciência e saber. Para ele, "o saber, ao contrário da ciência, é o conhecimento mundano carente de autonomia formal e gnosiológica, visto se desenvolver em conexão com as práticas sociais e o processo histórico abrangente, através da mediação do que chamou de episteme.”.
} 
que o conhecimento ambiental requer perspectivas que contemplem novas relações entre as disciplinas, que resultem em algo para além de sua simples soma. Assim, o campo ambiental abrange um objeto situado nas fronteiras disciplinares - o meio ambiente - e implica a compreensão de outra racionalidade para avançar nas respostas para suas problemáticas.

A escolha pela proposta interdisciplinar não significa querer extinguir as disciplinas, mas sim fomentar uma troca de conhecimento entre elas, a fim de dar conta de fenômenos complexos ou também chamados "de fronteira", como é o caso do meio ambiente. Como diz Raynaut (2004, p. 27), "os problemas decorrentes do campo ambiental reclamam uma ótica que destaque as inter-relações entre fenômenos, as correspondências entre níveis de organização e a imbricação de ligações causais".

O reconhecimento desse campo começa a surgir nos anos 1960, perante o crescimento e a visibilização da deterioração ambiental. É nessa época também que as críticas ao modelo industrial e ao progresso tecnológico começam a ser mais intensas (Costa, 2005), e que se intensifica o debate sobre o próprio modelo de ciência preponderante. Ao questionar a fragilidade da ciência moderna, disciplinar, e os desafios apresentados a partir da crise socioambiental oriunda de um paradigma cartesiano e economicista, Leff (2001a; 2001b) propõe a reflexão sobre uma epistemologia própria de um campo centrado nas questões ambientais, mas construído de forma partilhada a partir de conexões entre diferentes áreas de saber e conhecimento.

Diante disso, o campo ambiental se sustenta por outra forma de pensar, por uma racionalidade diferente daquela hegemônica. Leff (2001b) afirma que a racionalidade ambiental está baseada em uma nova ética, na qual a harmonia entre humanos e natureza - e os princípios de uma vida democrática e de valores culturais que dão sentido à existência humana — poderiam levar a transformações práticas na estrutura de poder associada à ordem estabelecida, responsável pelo desencadeamento de desequilíbrios ecológicos em escala planetária. Essa racionalidade interpreta o meio ambiente de forma plena, percebendo suas complexidades e reconhecendo um sistema de valores vinculado a novos potenciais de desenvolvimento e a uma diversidade de saberes e estilos culturais de vida. A ênfase desse pensamento está na pluralidade, interdependência e complexidade.

A complexidade ambiental, de acordo ainda com Leff (2001a), incorpora incertezas, caos e riscos, revelando limites do conhecimento e da incompletude do ser. Também abre espaço para reconhecermos o mundo, em que vivemos, implicando "[...] uma transformação do conhecimento e das práticas educativas, para se construir um novo saber, uma nova racionalidade que orientem a construção de um mundo de sustentabilidade, de equidade, de democracia" (Leff, 2001a, p. 196).

De maneira semelhante, Morin \& Kern (2002) defendem a necessidade de se reformar o pensamento, de complexificá-lo. A complexidade seria uma alternativa ao paradigma cartesiano para enfrentar o emaranhado de conexões existentes entre os fenômenos; seria uma proposta para ultrapassar o entendimento fragmentado, sem jamais homogeneizá-lo. A ideia é centrada em um movimento dialógico entre ordem, desordem, interações e organização, que tem como finalidade religar os saberes e apresentar o caráter multidimensional de toda realidade.

Assim, a conformação do campo ambiental reúne diferentes perspectivas e saberes que abarcam a relação sociedade-natureza com o propósito de refletir, analisar e propor soluções para as questões socioambientais. Em função disso, reivindica a necessidade de constantes trocas entre os mais diversos campos (práticas interdisciplinares), pois parte do pressuposto de que o meio ambiente precisa ser apreendido não como mais um objeto da ciência moderna (que é reduzido e simplificado), mas percebido em toda a sua complexidade.

\subsection{O campo comunicacional}

Para além dos grandes entendimentos conceituais, interessa aqui situar também a comunicação como ciência interdisciplinar por excelência. Del Vecchio de Lima (2002, p. 31) ressalta que Bougnoux (1994) é incisivo quando diz que as ciências da informação e da comunicação "correspondem, no momento histórico atual, a uma forte demanda social (e pedagógica), a uma virada em nossa cultura, tanto quanto ao advento de novos modelos". Além disso, como meio de partilha de ideias e 
troca interpessoal, a comunicação é uma característica e uma necessidade fundamental que acompanha a espécie humana desde os seus primórdios (Wolton, 2004).

Embora existam várias teorias da comunicação, não é possível apontar uma diferenciação significativa que determine o campo comunicacional indubitavelmente perante outros - sua epistemologia ainda está em formação e em constante discussão. Nele a própria noção do que é comunicação pode ser tomada por vários enfoques. Para Wolton (2004), ela se constitui em duas dimensões: a funcional (instrumental, ligada ao trabalho de difusão e transmissão) e a normativa (no sentido de partilha, comunhão e pleno diálogo). De acordo com o autor, a importância do pensamento teórico nesse campo vai além da performance dos instrumentos e técnicas ou do progresso da indústria da comunicação - ela advém da profunda ligação que a comunicação tem com a cultura ocidental moderna, sua constituição e seus valores fundamentais, como a noção de indivíduos e o seu modelo de relações sociais. Dessa maneira, pensar a comunicação em sua ambivalência constitui uma das novas utopias da cultura ocidental.

A comunicação só aparece como uma preocupação teórica no início do século XX, a partir das questões que alguns cientistas sociais passam a levantar diante da proliferação de equipamentos e fenômenos de produção e consumo de mensagens de massa, como a propaganda e os processos de eleições políticas na sociedade norte-americana. Os primeiros estudos acadêmicos surgem com uma abordagem empírico-crítica, instrumental e quantitativa, tendo como principal objeto os MCM, inseridos em uma sociedade e cultura de massa (Wolton, 2004).

A partir da década de 1960, junto com as mudanças que ocorrem na própria sociedade, o foco dos trabalhos deixa de ser os MCM e a comunicação como um instrumento, dando espaço à sua concepção como um processo de interação entre pessoas e grupos nas mais diversas instâncias. Passa-se a analisar as mediações sociais envolvidas na comunicação enquanto processo, com metodologias mais qualitativas e temáticas voltadas à cultura e às novas tecnologias, como fez, e continua a fazer, Martin-Barbero (2001), para apontar um autor da América Latina.
Tais mediações vêm se intensificando nas últimas décadas com o conjunto de fenômenos condicionados pelas novas mídias digitais, como a internet. Assim, a noção de comunicação já não se resume a processos de informação ou mesmo de conversação. Trata-se de um fluxo de interação contínuo, em uma sociedade midiatizada, em que o indivíduo pode não só dialogar com os "emissores" das mensagens que recebe, mas também passá-las adiante com grande alcance, a partir de suas leituras e interpretações (Braga, 2011). Como explica o autor, nessa sociedade a interação se manifesta como um fluxo sempre adiante:

Com a emissão de uma mensagem, [...] o "receptor", após apropriação de seu sentido (o que implica a incidência das mediações acionadas), pode sempre repor no espaço social suas interpretações. Isso ocorrerá seja em presencialidade (em conversações, justamente), seja por outras inserções midiatizadas - cartas, redes sociais, vídeos, novas produções empresariais, blogs, observatórios etc. Os circuitos aí acionados - muito mais abrangentes, difusos, diferidos e complexos - é que constituem o espaço das respostas "adiante" na interação social. (Braga, 2011, p. 68).

Em consonância com os questionamentos do modo moderno de fazer ciência, a partir da década de 1990 surgem novas reflexões sobre o que é próprio do campo da comunicação, levando em conta perspectivas como a da complexidade. França (2001) pondera a respeito da necessidade de superação do "paradigma informacional", que descreve a comunicação como um processo simplificado de emissão e recepção de mensagens. Para a autora, o que caracteriza o campo não são os objetos que lhe poderiam ser próprios, mas a abordagem comunicacional de um fenômeno, o olhar próprio que permite a construção e o estudo de um objeto em seu caráter comunicacional.

Logo, o campo comunicacional passa a abarcar uma ampla variedade de objetos. Nele, todo e qualquer fato humano é problematizável sob o enfoque da interação/comunicação, uma vez que o fenômeno comunicacional atravessa todas as atividades humanas e sociais (Braga, 2011). É importante dizer que também 
a comunicação se torna objeto de outros campos. Em tal compartilhamento, sua contribuição para as Ciências Sociais e Humanas estaria, conforme Braga (2011), não na busca por delimitar seu território específico, mas em desenvolver questões para além das que já são feitas pelas outras disciplinas.

O campo da comunicação se apresenta, assim, por natureza, como interdisciplinar (Braga, 2011) - não só por compartilhar conhecimentos e metodologias com outros campos, mas por conta das várias interfaces que possui. É possível pensar, por exemplo, nas interfaces da comunicação com os campos da educação, da política e do meio ambiente, entre vários outros.

\subsection{A comunicação ambiental como interface entre os dois campos}

Como visto, os campos comunicacional e ambiental são, por sua natureza, interdisciplinares. O primeiro está presente em todos os campos do conhecimento, uma vez que toda ciência faz o uso das ferramentas/processos de comunicação para divulgar seus avanços e descobertas à sociedade, além do fato da comunicação ser, antes de tudo, o estabelecimento de uma relação com o outro. $\mathrm{O}$ segundo também aparece em diferentes disciplinas, ainda que de forma fragmentada, reivindicando na formação de seu campo uma visão ampla e holística para que seja possível identificar e solucionar a complexidade inerente à sua constituição como espaço de disputas e de sobrevivência. No encontro dessas duas áreas de conhecimento abrangentes, porém com fundamentos específicos, nasce o termo "comunicação ambiental", no qual se articulam questões dos dois campos, em prol de uma comunicação mais qualificada a respeito dos problemas socioambientais. Tal conceito integra interesses e preocupações que convergem para o esclarecimento e, mais que isso, para o empoderamento dos cidadãos para intervir na realidade de forma mais consciente e/ou responsável.

Conforme Hannigan (2009), na passagem dos problemas ambientais de "condições" para "assuntos" e, depois, para "condicionantes" da elaboração de políticas públicas, a visibilidade midiática é crucial, pois sem a cobertura dos MCM, é pouco provável que problemas antigos entrem na área do discurso público ou venham a fazer parte do processo político. Concorda-se com o autor sobre as potencialidades dos MCM, porém os fluxos comunicacionais - especialmente no cenário das redes da internet - não se limitam ao papel da mídia hegemônica. Complementa-se que muitos arranjos comunicacionais ditos alternativos atuam de forma estratégica para disseminar informações socioambientais que façam os receptores pensarem, agirem e se mobilizarem (o ativismo digital realizado nas redes sociais a favor do veto presidencial sobre a decisão do Código Florestal Brasileiro, em 2012, é um exemplo disso).

Constata-se que nos últimos anos houve um aumento significativo nas publicações, reportagens e documentários sobre o meio ambiente, e a busca progressiva de muitas empresas e instituições públicas e privadas de vincular suas imagens à defesa ambiental, por meio de campanhas publicitárias, selos de certificação e patrocínio de eventos ecológicos. A comunicação ambiental é praticada e expandida nos mais diversos setores, a fim de levantar reflexões e despertar indagações sobre a maneira da sociedade se relacionar com o meio do qual depende, embora nem sempre consiga alcançar seus objetivos em razão da falta de qualificação e/ou de compreensão dos campos daqueles que são responsáveis pelo processo.

Para Cox (2009), a comunicação ambiental é um "campo multidisciplinar" de estudos e práticas ou maneiras de influenciar a vida diária na mídia, nos negócios, nos assuntos de governo e na sociedade civil. É uma concepção abrangente, que pode ser vinculada à perspectiva de interface. Mei (2013, p. 78), ao rever as reflexões de Cox, assinala que "a comunicação ambiental é pragmática e constitutiva”. Pragmática porque, por meio de campanhas, pode ser educativa e ter a finalidade de alertar para os problemas ambientais, bem como persuadir e ajudar a solucionar os problemas dessa natureza; e constitutiva pela capacidade de contribuir para a construção de representações sobre meio ambiente. A comunicação ambiental ajuda a transformar certas questões em problemas, mudando, aos poucos, nossa consciência sobre o que ocorre no planeta; e, ao promover o debate, pode construir esferas de influência, criando espaços para a construção coletiva e a discussão de ideias. 
Por sua vez, Depoe (2010) define comunicação ambiental como as relações entre os discursos e as nossas experiências com o meio ambiental natural, advertindo que ela vai além de simplesmente falar sobre o meio ambiente. Complementando essa ideia, Jurin et al. (2010, p. 14) consideram que o termo contempla todas as formas de relações que "compõem a discussão social, o debate sobre questões e problemas ambientais, bem como o nosso relacionamento de natureza não humana". Nesses autores, de forma mais ou menos explícita, está contida a ideia de ligação, de relação, entre ambiente e ser humano.

Já Bueno (2007, p. 30) define a expressão como "todo conjunto de ações, estratégias, produtos, planos e esforços de comunicação destinados a promover a divulgação/promoção da causa ambiental". O autor também compreende por comunicação ambiental as peças de comunicação, como folhetos e cartazes, campanhas publicitárias, palestras, manifestações, vídeos, filmes e livros sobre temas ambientais.

Embora tais trabalhos não aprofundem a questão epistemológica do encontro entre os dois campos do conhecimento, a comunicação ambiental é caracterizada, em meio às definições apresentadas, pela pluralidade, profundidade e vocação em promover debates e ações transformadoras perante questões socioambientais elementos presentes na epistemologia ambiental e no entendimento da comunicação em sua essência. Acredita-se que o desafio primordial ao se adotar uma perspectiva interdisciplinar entre meio ambiente e comunicação é procurar restituir, ainda que de maneira parcial, o caráter de totalidade e de complexidade do mundo real dentro do qual e sobre o qual indivíduos e sociedade pretendem atuar. Essa tentativa pode ser bastante eficaz nesse momento, ou seja, diante do crescimento da diversidade midiática promovida pela evolução digital, estando aí também o aumento das potencialidades da comunicação para auxiliar no enfrentamento dos problemas socioambientais que se acumulam.

A ampliação do acesso e dos produtos de comunicação ambiental permite que um número cada vez maior de pessoas em todo o mundo tenha conhecimento sobre essas questões, proporcionando reflexão e possibilidade de reação, embora também imobilize uma parte da sociedade em razão do imenso fluxo de informações sobre aspectos ambientais atrelados à negatividade, o que cria uma sensação de risco, medo, impotência em âmbito global. Aguiar \& Schaun (2011) realizaram estudos nos quais perceberam que a imprensa tende a vincular a crise socioambiental a uma heurística do medo, em que a ideia de negatividade acaba por esvaziar a possibilidade de ação política. Em relação à imprensa, Bueno (2007, p. 36) também aponta que a cobertura de meio ambiente tende a ser "refém de ações mercadológicas ou empresariais e interesses políticos". Nesse contexto, impõe-se a superficialidade nas abordagens, com ênfase em pautas que contemplam catástrofes.

Em outras palavras, grande parte das informações difundidas pela mídia hegemônica está construída de modo a alertar para o risco dos problemas ambientais sem incluir muitas discussões em relação ao que se pode fazer a respeito. Isso confirma que nem toda informação de meio ambiente está relacionada à comunicação ambiental entendida como área especializada na interface dos campos ambiental e comunicacional. Pode-se falar, nesses casos, em uma "comunicação de meio ambiente", que se resume a abordar temas característicos da área ambiental.

\section{A comunicação ambiental no enfrentamento dos problemas socioambientais}

Ao tentar caracterizar o que é comunicação ambiental, percebe-se uma gama de fatores que determinam tal definição, dos epistemológicos até aqueles mais concretos (os produtos da comunicação), dando margem a inúmeras interpretações, muitas vezes até contraditórias. Pela vastidão de processos e produtos comunicacionais existentes e pela complexidade que envolve o meio ambiente, a comunicação ambiental, pela simples associação dos dois termos, passa a ser percebida, inadvertidamente, como qualquer tipo de comunicação que aborde aspectos ambientais. Como a própria definição de meio ambiente é abrangente e nem sempre integra os aspectos sociais e naturais, para verificar as possibilidades da comunicação para enfrentar as crises que estão colocadas, este grupo de pesquisadores entende que a compreensão do termo abrange o conhecimento e a incorporação dos aspectos epistemológicos do campo 
ambiental (interdisciplinaridade, complexidade, olhar holístico, racionalidade integradora e ética do homem com a natureza) interconectados com o cuidado de promover a relação com o outro, de maneira não instrumental, oriundo do campo comunicacional.

Além disso, o fazer da comunicação ambiental pressupõe a utilização dos fundamentos comunicacionais a favor do exercício da cidadania planetária ${ }^{4}$, que estimule ações transformadoras pela sustentabilidade do nosso meio, e, especialmente, do nosso "meio" mais próximo, aquele definido pelo nosso espaço local.

A construção de uma cidadania planetária tem ainda um longo caminho a percorrer no interior da globalização capitalista. [...] A cidadania planetária deverá ter como foco a superação da desigualdade, a eliminação das sangrentas diferenças econômicas e a integração da diversidade cultural da humanidade e a eliminação das diferenças econômicas. [...] Não se pode falar em cidadania planetária ou global sem uma efetiva cidadania na esfera local e nacional. Uma cidadania planetária é por essência uma cidadania integral, portanto, uma cidadania ativa e plena não apenas nos direitos sociais, políticos, culturais e institucionais, mas também econômico-financeiros. (Gadotti, 1998, p. 5-6).

Logo, ao se relacionar a comunicação com a ideia de cidadania planetária, exclui-se dessa concepção todo e qualquer tipo de comunicação que fale de meio ambiente de forma rasa, desconexa, descontextualizada e não instrutiva ou questionadora.

A comunicação, atenta aos fundamentos e concepções do meio ambiente, tem o potencial de agir de forma contundente nas três fases relacionadas aos problemas socioambientais: a prevenção (o que fazer para evitar os problemas), a mitigação (para reduzi-los ou remediá-los) e a adaptação (relacionada ao que pode ser feito depois que o problema não pode mais ser evitado nem remediado). Tais etapas são apresentadas por Marandola Jr. (2009) ao tratar dos riscos socioambientais, porém podem ser transpostas nesse contexto, a fim de sublinhar o papel da comunicação ambiental na base das resoluções políticas, administrativas e de participação cidadã. Afinal, sem o entendimento do que pode e precisa ser feito, das possibilidades de atuação e dos imbricamentos da relação sociedade-natureza, não há como exigir práticas e técnicas eficazes para o enfrentamento das crises.

Defende-se aqui a construção e a concepção da comunicação ambiental a ser pensada em prol de uma real compreensão dos efeitos das mudanças ambientais e do despertar da cidadania, contribuindo para a participação política e, posteriormente, quiçá, uma mobilização global. Nesse contexto, para que o efetivo exercício da cidadania em relação ao meio ambiente seja possível, é preciso que exista acesso à informação de qualidade e produção de conhecimentos que permitam o empoderamento dos interlocutores. Girardi et al. (2011, p. 112-113) destacam o papel essencial da comunicação na construção da cidadania, que:

[...] permite aos cidadãos terem acesso às informações que esclarecem questões fundamentais para a tomada de decisões referentes à esfera pública, além da participação mais ativa da sociedade. Esse direito à informação refere-se não apenas ao direito de ser informado, mas também ao direito de informar, de expressar interesses e opiniões.

Dessa forma, a fim de que se promova o exercício da cidadania é preciso, antes, que circulem informações qualificadas sobre as problemáticas ambientais, e não somente alarmismo e negatividade. A cidadania ambiental traz em sua concepção o estabelecimento de outras formas de relação ser humano-natureza, diferente da dominação daquele sobre esta (visão hegemônica até então), de caráter mais equilibrado, harmônico e

\footnotetext{
4 “A noção de cidadania planetária (mundial) sustenta-se na visão unificadora do planeta e de uma sociedade mundial. Ela se manifesta em diferentes expressões: 'nossa humanidade comum', 'unidade na diversidade', 'nosso futuro comum', 'nossa pátria comum'. Cidadania planetária é uma expressão adotada para expressar um conjunto de princípios, valores, atitudes e comportamentos que demonstra uma nova percepção da Terra como uma única comunidade (Boff, 1995). Frequentemente associada ao "desenvolvimento sustentável", é muito mais ampla do que essa relação com a economia. Trata-se de um ponto de referência ético indissociável da civilização planetária e da ecologia” (Gadotti, 1998, p. 2).
} 
condizente com o fato de que somos todos habitantes de um mesmo planeta.

Ademais, na sociedade em rede, a autonomia das escolhas de decisão está diretamente ligada à capacidade de interação com a mídia, aqui compreendida como todos os processos e estratégias de mediação e acesso à comunicação e à informação. Portanto, quando se soma a comunicação interpessoal a novas fontes e a novos destinos, criam-se novas redes interligando diferentes mídias. Isso confere à sociedade a característica de expressar uma "cidadania ambiental", com a qual a resposta aos problemas ambientais funciona nos termos e nas condições dos próprios cidadãos, em vez de ser estruturada por atividades conduzidas pelo Estado, pelo mercado ou por outras instâncias de poder.

Assim, pode-se retratar a cidadania ambiental como representando uma pressão "vinda de baixo", uma não conformação com o enquadramento decidido "acima", e voltada para refletir, expressar, planejar ações e práticas de enfrentamento aos dilemas socioambientais, em todos os âmbitos físicos (naturais em si), sociais, econômicos e culturais que se manifestam em diferentes espacialidades.

Enfim, para o enfrentamento das crises socioambientais, aposta-se em uma comunicação mais atenta aos princípios socioambientais, ultrapassando a ideia de que o meio ambiente é apenas mais um tema que deve ser trabalhado pelo campo comunicacional. Como espaço de integração dos dois campos em questão, a comunicação ambiental é um processo fundamental para confrontar os dilemas postos, por constituir o primeiro passo para o entendimento e a reflexão que, posteriormente, poderá levar a práticas em prol de mudanças.

\section{Considerações finais}

Com base nas discussões apresentadas, ressalta-se a existência de uma diferenciação entre "comunicação de meio ambiente" e "comunicação ambiental". Enquanto a primeira se resume a falar de temas relacionados ao meio ambiente, a segunda se constitui como área de interface entre os campos comunicacional e ambiental, incorporando princípios de ambos na abordagem das questões socioambientais.

A partir do esforço analítico-reflexivo realizado para apontar as potencialidades da comunicação ambiental no enfrentamento de tais questões, admite-se que esta se trata de um "vir a ser" - algo ainda em construção, tanto do ponto de vista teórico quanto prático. Cabe debater, inclusive, quais seriam os espaços e as possibilidades de concretização de uma comunicação ambiental efetiva na realidade atual, o que o grupo de pesquisa, em que se inserem os autores deste artigo, vem desenvolvendo por meio de reflexões e trabalhos.

De todo modo, mesmo sendo ainda um campo em formação com possibilidades de construção ainda abertas e com necessidade do acréscimo de novas contribuições à investigação teórica e empírica na área, não se pode deixar de lado a importância que o campo já ocupa para o encaminhamento de soluções para as grandes problemáticas socioambientais.

Como salienta o sociólogo Arthur Mol (2008), na Era da Informação, a mídia tem se tornado um ponto-chave na governança ambiental, assim como um fator fundamental em tantos outros campos. E a governança competente e democrática, com mecanismos de estímulo à participação cidadã, é uma das estratégias para o enfrentamento dos problemas socioambientais contemporâneos.

Nesse sentido, torna-se necessário lançar um olhar mais amplo para um processo circular: a mídia como ferramenta comunicacional e como esfera de debate público, simultaneamente, insere-se no campo das intensas trocas interacionais e de experiências comunicacionais que se estendem muito além dela, o que sinaliza, novamente, para a importância da comunicação ambiental como campo epistemológico e praxiológico, no qual a mídia se localiza. 


\section{Referências}

Aguiar, L. A.; Schaun, A. Heurística do medo: mídia e meio ambiente na sociedade de risco. Revista Ação Midiática: Estudos em Comunicação, Sociedade e Cultura, 1(2), 2011. doi: http://dx.doi.org/10.5380/am.v0i2.26423.

Bougnoux, D. Introdução às ciências da informação e da comunicação. Petrópolis, RJ: Vozes, 1994.

Braga, J. L. Constituição do campo da comunicação. Revista Verso e Reverso, 25(58), 62-77, 2011. doi: 10.4013/ ver.2011.25.58.07.

Bueno, W. C. Comunicação, jornalismo e meio ambiente: teoria e pesquisa. São Paulo: Mojoara Ed., 2007.

Castells, M. A sociedade em rede. São Paulo: Paz e Terra, 1999.

Cox, R. Environmental communication and the public sphere. Thousands Oaks, California: Sage Publications, 2009.

Costa, L. M. A formação do campo ambiental: um resgate histórico do contexto nacional e amazônico. Revista Tempo da Ciência, 12,147-176, 2005. Disponível em: file://C:/Users/ CLIENTE/Downloads/439-1500-1-PB\%20(1).pdf

Del Vecchio de Lima, M. R. Comunicação, ambiente urbano e desenvolvimento: elementos para a compreensão do papel da informação na gestão do lixo em Curitiba. Curitiba, Tese (doutorado em Meio Ambiente e Desenvolvimento) — UFPR, 2002.

Depoe, S. P. Environmental communication: challenges and opportunities. West Lafayette, Indiana, USA: Purdue University, 2010.

Felinto, E. Os riscos da prudência: teoria da comunicação, disciplinaridade e a comunicologia de Vilém Flusser. In: França, V.; Aldé, A.; Ramos, M. C. (Orgs.). Teorias da comunicação no Brasil: reflexões contemporâneas. Salvador: Edufba, p.2137, 2014.

França, V. Paradigmas da comunicação: conhecer o quê? Ciberlegenda, 5, 2001. Disponível em: http://www.uff.br/ ciberlegenda/ojs/index.php/revista/article/view/314/195

Gadotti, M. Cidadania planetária: pontos para a reflexão. In: Anais da Conferência Continental das Américas para a Carta da Terra, 1998. Disponível em: http://siteantigo.paulofreire. org/pub/Institu/SubInstitucional1203023491It003Ps002/Cidadania_Plenataria_1998.pdf

Girardi, I. M. T.; Loose, E. B.; Sirena, M.; Pedroso, R. N. Jornalismo ambiental na construção da cidadania. In: Morigi,
V. J.; Girardi, I. M. T.; Almeida, C. D. (Orgs.). Comunicação, informação e cidadania: refletindo práticas e contextos. Porto Alegre: Sulina, 2011.

Hannigan, J. Sociologia ambiental. Petrópolis, RJ: Vozes, 2009.

Jurin, R.; Roush, D.; Danter, K. J. Environmental communication: skills and principles for natural resource managers, scientists and engineers. New York: Springer, 2010.

Leff, E. Epistemologia ambiental. São Paulo: Editora Cortez, 2001a.

Leff, E. Saber ambiental: sustentabilidade, racionalidade, complexidade, poder. Petrópolis, RJ: Vozes/Pnuma, 2001b.

Leff, E. Racionalidade ambiental: a reapropriação social da natureza. Rio de Janeiro: Civilização Brasileira, 2006.

Martin-Barbero, J. Dos meios às mediações: comunicação, cultura e hegemonia. Rio de Janeiro: Editora UFRJ, 2001.

Mei, D. S. Comunicação e mobilização social: o caso do Fórum Permanente da Agenda 21 no Paraná. Curitiba, Dissertação (mestrado em Comunicação) — UFPR 2013.

Marandola Jr., E. Tangenciando a vulnerabilidade. In: Hogan, D.; Marandola Jr., E. (Orgs.). População e mudança climática: dimensões humanas das mudanças ambientais globais. Campinas: Núcleo de Estudos de População (Nepo)/Unicamp; Brasília: UNFPA, p.29-52, 2009.

Mol, A. P. J. Environmental reform in the information age: the contours of Informational Governance. New York, USA: Cambridge University Press. 2008.

Morin, E.; Kern, A. Terra-pátria. Porto Alegre: Sulina, 2002.

Raynaut, C. Meio ambiente e desenvolvimento: construindo um novo campo do saber a partir da perspectiva interdisciplinar. Desenvolvimento e Meio Ambiente, 10, 21-32, 2004. doi: http:// dx.doi.org/10.5380/dma.v10i0.3089

Rüdiger, F. Teoria e história: da era da propaganda ao pensamento comunicacional. In: França, V.; Aldé, A.; Ramos, M. C. (Orgs.). Teorias da comunicação no Brasil: reflexões contemporâneas. Salvador: Edufba, p. 39-61, 2014.

Wolton, D. Pensar a comunicação. Brasília: Editora da UnB, 2004. 